\title{
Two prelicensure nursing programs assess readiness to standardize palliative and end of life care curriculum
}

\author{
Andra L. Davis*1, Megan E. Lippe ${ }^{2}$ \\ ${ }^{1}$ College of Nursing, Washington State University, Vancouver, WA, United States \\ ${ }^{2}$ Capstone College of Nursing, University of Alabama, Tuscaloosa, AL, United States
}

Received: August 9, 2017

DOI: $10.5430 /$ jnep.v8n2p29
Accepted: September 21, 2017 Online Published: November 10, 2017

URL: https://doi.org/10.5430/jnep.v8n2p29

\begin{abstract}
There is a growing imperative for nurses to be adequately trained to care for patients with serious, life-limiting illness. However, the current nursing education system requires vast content areas be taught, resulting in minimal emphasize on palliative and end-of-life care and inadequate preparation of nurses to care for dying patients upon entering practice. To address the need for enhanced palliative and end-of-life care integration within their respective programs, two universities conducted needs assessments to determine the best next steps in enhancing student preparation to care for patients with serious, life-limiting illness. One university engaged in a three-part needs assessment resulting in the formation of an ad hoc committee to guide discussions for content integration. The second university engaged in a faculty-led survey to identify areas for improvement within the program. The purpose of this paper is to describe the processes and challenges encountered by both schools to aid other programs that may be considering or preparing for a similar endeavor.
\end{abstract}

Key Words: Nursing education, Palliative care, End of life, Program evaluation, Needs assessment, Nursing curriculum

\section{INTRODUCTION}

The national platform among professional organizations recognizes discrepancies and gaps in care for persons with serious, life-limiting illness. ${ }^{[1-3]}$ Substantial evidence exists that access to palliative and end-of-life (PEOL) care improves patient outcomes, quality of life, and contributes to system sustainability. ${ }^{[2,4]}$ National recommendations call for all healthcare providers caring for persons with serious illness to be equipped with primary palliative care skills and knowledge, regardless of practice setting. ${ }^{[1,2,5]}$ Palliative care requires the management of "physical, intellectual, emotional, social, and spiritual needs" of patients and their families with a focus on the prevention and treatment of suffering. ${ }^{[6]}$ Nurses are positioned to lead in transforming palliative care practice; however, they lack the requisite primary skills and knowledge preparation.

In most healthcare settings, nurses care for persons with life-limiting illness and spend more time with persons at the end of life than other healthcare providers. ${ }^{[7]}$ Despite this high requirement to provide PEOL care, nurses consistently report feeling inadequately prepared to do so. ${ }^{[7,8]}$ Nurses and nursing students have long reported feeling anxious and lacking in communication skills to address PEOL issues with patients and their families. ${ }^{[9,10]}$

Education for specialty and primary palliative care training exists for practicing nurses; however, formal curricular integration of PEOL care in undergraduate nursing programs is

\footnotetext{
*Correspondence: Andra L. Davis; Email: andra.davis@wsu.edu; Address: College of Nursing, Washington State University, Vancouver, WA, United States.
}

Published by Sciedu Press 
insufficient. ${ }^{[11,12]}$ In a combined call to action, the American Nurses Association and Hospice and Palliative Nurses Association partnered to recommend that End of Life Nursing Education Consortium (ELNEC) curricula, specifically the recently released undergraduate modules, become the standard for PEOL pre-licensure nursing education. ${ }^{[1]}$ ELNEC Core, an evidence-based continuing education curriculum for practicing nurses developed by leaders in the field, has been widely disseminated internationally for over 16 years. ${ }^{[3]}$ To address the gap in PEOL domains of care in pre-licensure nursing education, an online, undergraduate version of the ELNEC curriculum was developed. ${ }^{[3]}$ This new online curriculum adapted the ELNEC Core curriculum, designed for practicing nurses, to fit the educational needs of undergraduate students.

Adding new content to an already crowded curriculum is an unyielding barrier for nurse educators; ${ }^{[13]}$ therefore, curricular revision to integrate ELNEC content must be considered carefully. Competing factors take center stage in curricular revisions such as adherence to accreditation standards and maintaining high numbers of student first-time licensure pass rates. The AACN has outlined nine key essentials areas of content required for accreditation purposes. ${ }^{[14]}$ Such required topics include aspects of leadership, interprofessional communication, population health, ethics, and evidence based practice, to name a few. Collectively, there are 109 critical elements across the nine essentials, only one of which pertains to PEOL care $(0.9 \%)$. Similarly, accreditation bodies critically evaluate nursing programs on their students' success in passing licensure exams on the first attempt, forcing educators to devote much instruction and attention to ensuring all required content is addressed in a curriculum. Four primary licensure areas focus on safe and effective care environment, health promotion and maintenance, psychosocial integrity, and physiological integrity. ${ }^{[15]}$ PEOL care is one of sixteen possible items covered within the psychosocial category, representing $6 \%-12 \%$ of exam content within that primary domain. ${ }^{[15]}$ Therefore, students are likely to see either one or no questions related to PEOL on their licensure exam. Faculty may focus on elements aligning with other non-PEOL content areas, thus lowering the priority for PEOL education.

While meeting accreditation standards is essential to high quality education, the imperative to standardize entrylevel professional education in PEOL must be part of the current narrative. Providing PEOL education improves students' knowledge, attitudes, and perceived competence/confidence ${ }^{[16]}$ further emphasizing the importance of training nurses prior to entering professional practice. Reprioritization of this material should be considered in light of the recent ANA call to action and directive to participate in transforming PEOL education and practice. ${ }^{[1]}$

Among the many advantages of the online ELNEC modules are its completeness and adaptability within an existing curriculum structure. The comprehensive tutorials equip faculty with various levels of PEOL knowledge to successfully integrate these into existing courses. Finding creative ways to weave in the six in-depth modules (Principles of Palliative Care; Symptom Management; Pain Management; Communication; Loss-Grief-Bereavement; and Final Hours) is the challenge. ${ }^{[17]}$ The purpose of this paper is to describe two replicable needs assessments conducted in preparation for integrating ELNEC education in baccalaureate nursing programs.

\section{Methods}

\subsection{Assessing PEOL content in two undergraduate nurs- ing programs}

Both nursing programs utilized a formative evaluation process to assess PEOL content within their respective curricula. Formative evaluation provides critical information about a program prior to implementing change, allowing evaluators to gain a greater understanding of context, implications, and potential adaptation to change. ${ }^{[18]}$ Such evaluation is essential to making program changes by providing a source of 'currency' and facilitating the determination of academic and professional relevance. ${ }^{[19]}$ Formative evaluation serves as an organizing framework to determine what PEOL concepts are present in courses, identify potential faculty champions, and uncover gaps and opportunities for improvement. ${ }^{[19]}$ Both exemplar needs assessments presented in this paper used the ELNEC Core Curricular domains ${ }^{[3]}$ to structure their respective assessment processes. Using different approaches at each school, both programs respectfully engaged in a comprehensive curricular assessment to determine 1) PEOL concepts already existing in the curriculum; 2) identify gaps and redundancies in PEOL content across courses, and 3) explore opportunities to creatively integrate ELNEC modules into courses. Both programs felt it was a priority to build upon existing PEOL content, supporting faculty that were philosophically aligned with the importance of PEOL education, and not dismissing their efforts by replacing existing material with ELNEC modules. The first university engaged in a committee- and administration-driven curricular assessment using mixed methods for data collection. The second university engaged in an instructor- and theory-driven assessment using quantitative data. Both approaches will be described, followed by a discussion and comparison of the respective approaches. 


\subsubsection{University 1 needs assessment}

The first university, a large statewide multi-campus school in the northwestern United States, engaged in a three-part needs assessment seeking to: 1) Assess PEOL concepts present in the curriculum, 2) Identify gaps and redundancy, and 3) Explore opportunities to incorporate the online ELNEC modules. As part of formative evaluation, baseline information was collected using mixed methods. The initial phase gathered quantitative and qualitative baseline data for three months prior to developing a plan for potential curricular revision. All undergraduate faculty received an email inquiry modeled after a survey conducted during an ELNEC training for nurse educators. ${ }^{[17]}$ At the ELNEC training, facultyattendees identified ELNEC domains currently taught in their respective programs and estimated the number of classroom hours used on each domain. Using a 0-10 scale, perceptions of how prepared the students were by graduation in these same domains $(0=$ Not at all prepared, to $10=$ Very prepared $)$ was also rated. Additional narrative feedback was solicited and analyzed.

In the second phase of the assessment, a small group of champions were identified as individuals that had intentionally included PEOL content in their respective course. Results from the surveys became the foundation for engaging all undergraduate faculty in a discussion about PEOL education, becoming a regular agenda item during faculty meetings over the course of three months. First, a brief orientation to national expectations for palliative care competence was pre- sented to faculty, outlining national imperatives to improve PEOL education and providing an overview of the online ELNEC modules. ${ }^{[17]}$ It was critical at this stage to acknowledge the positive attributes of PEOL content that already existed, commending select faculty members for their efforts. A goal of the initiative was to expand rather than replace existing PEOL content, while equally valuing the importance of ensuring foundational standardized evidence-based principles to be incorporated in the existing curriculum and the quality PEOL content already being taught. Faculty formed an ad hoc committee to explore possible avenues for integration in the existing curricular structure.

In the final phase of the needs assessment, three options emerged from the committee work and were presented to the undergraduate faculty (see Table 1). The options included: 1) a "test and learn" option integrating ELNEC modules throughout junior semesters, 2) developing a standalone online course, or 3 ) decline to make changes. The undergraduate faculty supported a 'test and learn' approach, rather than a definitive change, with assurances that instructors would receive support during implementation. The school is in the second semester of the pilot. Quantitative and qualitative data will be gathered from faculty and students regarding incorporation of ELNEC modules into existing courses. A summary of findings will be presented at the end of the term and undergraduate faculty will decide next steps towards formalizing the existing plan or modifying.

Table 1. Implementation options at location 1

\begin{tabular}{|l}
\hline 1 Conduct a pilot 'test and learn' module for one year. \\
a. Integrate 6 modules across identified courses spanning Junior semesters one and two \\
I. Course instructor either independently incorporate module and facilitate learning or \\
II. ELNEC-trained faculty members to guest lecture and provide support \\
III. Interested faculty to receive orientation/training to each course-designated module \\
IV. ELNEC facilitator to report back to undergraduate committee at the end of semester one and two, updating on findings. \\
V. Undergraduate committee to make determination about continuing modules \\
2 Develop an online course \\
a. Delivery of all 6 modules to be completed by the end of Junior level \\
b. Shared delivery of content by ELNEC training faculty members \\
3 Decline to integrate online ELNEC modules \\
a. Continue informal integration of PEOL topics as they currently exist
\end{tabular}

\subsubsection{University 2 needs assessment}

Preliminary steps at the second university, a large, research intensive public university in the southern United States, were guided by an in-depth review of the literature to identify teaching strategies utilized related to ELNEC curriculum, such as simulation, case studies, reflection, lecture, clinical conference debriefing, films, and readings. ${ }^{[20]}$ All content areas within the ELNEC Core Curriculum were identified using a decomposition method. This information was compiled into a survey assessing the strategies utilized to teach ELNEC content in all undergraduate courses in the curriculum.

Following IRB approval, all undergraduate faculty members were requested to voluntarily participate in the survey. Re- 
minder emails were sent at two additional time points in the semester, providing faculty members with three invitations to participate in the survey. Faculty members completed one survey while providing responses for more than one course by reporting respective course names or numbers via free text entry responses to all survey items.

Analysis of survey results uncovered detailed information regarding PEOL content integration within the curriculum. The results revealed that principles of palliative care and care of the dying patient were primarily missing across the curriculum. Interestingly, analysis also revealed many content areas related to pain and symptom management that were covered extensively, or arguably redundantly. Variability was also identified within courses with multiple sections taught by various faculty members. Finally, results highlighted discrepancies in best practice expectations for PEOL education and current educational practice in the university.

The results of the survey were presented to the curriculum committee of the program. This information was of critical importance given major curriculum revisions that were underway. An understanding of the content within the cur- riculum, both missing and redundant, allowed for careful consideration of how to improve the curriculum moving forward. Specifically, an aging course in which much PEOL content was taught was being phased out of the program. The curriculum committee acknowledged the need to continue to cover the content that would be lost with the termination of the course, and identified the proper course for PEOL content integration.

\section{RESULTS AND DISCUSSION}

While each assessment process was different, both yielded detailed, critical information to guide curricular integration at the respective schools. Each university afforded different levels of administrative support for faculty workload credit during the implementation phase.

Table 2 summarizes the collective benefits and barriers experienced between the two universities. Both settings relied heavily on faculty responses to obtain complete data regarding existing curricular practices. The formative evaluation processes also heightened faculty awareness of the national imperative for PEOL nursing education.

Table 2. Benefits and barriers of both assessment approaches

\begin{tabular}{|c|c|}
\hline Benefits & Challenges \\
\hline $\begin{array}{l}\text { Dedicated faculty work release to planning and implementing } \\
\text { enhanced engagement when provided }\end{array}$ & $\begin{array}{l}\text { Faculty resources dedicated to assessment and implementation } \\
\text { phases had to be carefully balanced with competing demands }\end{array}$ \\
\hline Engaged key stakeholders, such as faculty and administrators & $\begin{array}{l}\text { Requires rigorous and regular communication to sustain the } \\
\text { interest and momentum }\end{array}$ \\
\hline $\begin{array}{l}\text { Illuminated existing PEOL content in courses and identified faculty } \\
\text { champions }\end{array}$ & $\begin{array}{l}\text { Concerns for costs of making change had to be carefully } \\
\text { navigated }\end{array}$ \\
\hline Identified gaps in PEOL topics & $\begin{array}{l}\text { Faculty training and support to ensure adequate PEOL } \\
\text { knowledge }\end{array}$ \\
\hline
\end{tabular}

Another benefit of both needs assessments was validation that some PEOL content was integrated within the curriculum, although for one university, existing content was not part of a curricular strategy, rather was in place because individual faculty believed it was a priority. The needs assessment also uncovered gaps in PEOL content, but highlighting these omissions gave faculty the opportunity to engage in careful considerations for curricular modifications.

Both approaches encountered challenges. Although the initiative was taken by only one faculty member at the first university and there was strong administrative support for the project, the undergraduate program is delivered on multiple campuses and was during a major curriculum revision. The distance challenged communication efforts and faculty were cautious about any changes because of upcoming larger curricular changes. Intense and regular communication was imperative due to the structure of multiple campuses. Ensuring a standardized and consistent implementation plan required faculty resources, including time for data collection and analysis as well as committee meetings. Faculty members had to carefully juggle their time allocated for the needs assessment and other teaching expectations. Furthermore, concerns voiced regarding added costs and resources needed to implement the change required carefully analysis and discussion.

At the second university, the needs assessment was generated from the interest of one faculty member; therefore, faculty participation was encouraged by peers, as opposed to administration. No workload credit was provided for faculty members to participate in the needs assessment. Despite the lack of administrative support, enough faculty members participated in the survey so that all courses within the program 
were represented in the results. The high response rate of colleagues (79\%) was a pleasant and unexpected surprise. Replication of this method in other programs will require similar levels of collegial support and cooperation.

Finally, for a needs assessment and subsequent curricular change to be successful, it was imperative to support course faculty that had limited knowledge of PEOL. Without an understanding of current best practice expectations and calls for action in PEOL education, faculty had limited ability to engage in informed conversations regarding this as an educational priority. Once faculty agreed to participate in integration of the ELNEC modules, ELNEC-trained colleagues supported those who recognized their limited understanding of best practices in this area. Collaboration occurred in person, through email, or by phone meetings, providing support to accommodate the self-identified educational needs of faculty across campuses. Additionally, trainers provided course faculty with examples of how to use the ELNEC learning activities, including case studies, communication vignettes, and emailed video recordings with examples of ways to debrief with students. Trainers also offered to provide direct classroom support when requested. Optimizing the faculty experience and knowledge of PEOL is critical for sustainability and standardization of curricular integration.

\section{Conclusions}

Conducting a needs assessment is a critical first step toward successful integration of primary PEOL education such that nursing students are prepared to enter professional practice with the skills and knowledge to engage in quality care for persons with life-limiting and serious illness. Identifying and confronting both the strengths and weaknesses of each school's PEOL curriculum created a climate of greater knowledge and creative problem-solving. Complexities of competing priorities and challenges exist with any curricular revision, requiring faculty member agility, innovation, and knowledge of national recommendations and mandates. We recognize that this paper addresses the experience of only two undergraduate nursing programs, as early adopters, we hope to provide some insight for others as they begin a similar endeavor. Transforming nursing practice begins by preparing nurses with the fundamentals for success within the current and future healthcare environment. Providing quality PEOL care is a foundational component of that preparation. In the case of these authors, taking the time to lay a foundation, educate faculty on national directions in transforming PEOL education and practice, and engaging them in identifying possible solutions, resulted in positive momentum and support for integration. Important next steps will be to develop evaluation methods to measure student learning outcomes such as knowledge, competency, and clinical performance in providing PEOL care.

The national discourse on PEOL care continues to gain momentum and nurses are integral to providing leadership in practice, policy, and education in the care of persons with serious, life-limiting illness. Quality education and training improves patient experiences as nurses are adequately prepared, resulting in nurses perceived improved confidence and reduced anxiety. ${ }^{[2,16,21]}$ Lindley and colleagues further suggest that nurses with palliative and hospice training are positioned to lead quality improvement efforts in PEOL. ${ }^{[22]}$ In this transformative time of advancements in PEOL care, as stated by the ANA president, Pamela Cipriano, "Every nurse should have the knowledge and ability to facilitate healing and alleviate suffering through the delivery of safe, quality, and holistic person-centered primary palliative care". ${ }^{[1]}$ The interactive online undergraduate ELNEC modules are an invaluable evidence-based resource. In staying aligned with the national directives to improve PEOL education and training, faculty and administration must form a shared vision that includes an exploration of creative approaches to integrate this content into baccalaureate education.

\section{CONFLicts OF INTEREST Disclosure}

The authors declare that there is no conflict of interest.

\section{REFERENCES}

[1] American Nurses Association. American Nurses Association and Hospice \& Palliative Nurses Association call for palliative care in every setting [Internet]. 2017 [cited 2017 Aug 5]. Available from: http://www.nursingworld.org/FunctionalMenuCategor ies/MediaResources/PressReleases/Call-for-Palliat ive-Care-in.html

[2] Institute of Medicine. Dying in America: Improving quality and honoring individual preferences near the end of life [Internet]. Washington, D.C.: The National
Academies Press; 2014 [cited 2014 Nov 23]. Available from: http://catalog/18748/dying-in-america-improving-q uality-and-honoring-individual-preferences-near

[3] American Association of Colleges of Nursing. ELNEC fact sheet [Internet]. 2016 [cited 2016 Sep 20]. Available from: http://www . aacn.nche.edu/elnec/about/fact-sheet

[4] Downey L, Au DH, Curtis JR, et al. Life-sustaining treatment preferences: Matches and mismatches between patients' preferences and clinicians' perceptions. J Pain Symptom Manage. 2013 Jul 1; 46(1): 90-19. PMid:23017611 https://doi.org/10.1016/j.jp 
ainsymman. 2012.07.002

[5] Center to Advance Palliative Care. Palliative care definitions and delivery models [Internet]. [cited 2017 Aug 5]. Available from: https : //www . capc .org/payers/palliative-care-definitions/

[6] National Consensus Project for Quality Palliative Care. Clinical practice guidelines for quality palliative care. 3rd ed. Pittsburgh, PA: National Consensus Project for Quality Palliative Care; 2013.

[7] Moreland SS, Lemieux ML, Myers A. End-of-life care and the use of simulation in a baccalaureate nursing program. Int $\mathbf{J}$ Nurs Educ Scholarsh. 2012 Jan; 9(1): 1-16. PMid:22673960 https: //doi.org/10.1515/1548-923X.2405

[8] Zheng R, Lee SF, Bloomer MJ. How new graduate nurses experience patient death: A systematic review and qualitative metasynthesis. Int J Nurs Stud. 2016; 53: 320-30. PMid:26493131 https://doi.org/10.1016/j.ijnurstu.2015.09.013

[9] Ferrell BR, Grant M, Virani R. Strengthening nursing education to improve end-of-life care. Nurs Outlook. 1999; 47(6): 252-6. https ://doi.org/10.1016/S0029-6554(99) 90022-2

[10] Kwekkeboom KL, Vahl C, Eland J. Impact of a volunteer companion program on nursing students' knowledge and concerns related to palliative care. J Palliat Med. 2006 Feb; 9(1): 90-9. PMid:16430349 https://doi.org/10.1089/jpm.2006.9.90

[11] Head BA, Schapmire T, Hermann C, et al. The Interdisciplinary Curriculum for Oncology Palliative Care Education (iCOPE): Meeting the challenge of interprofessional education. J Palliat Med. 2014; 17(10): 1107-1114. PMid:24972279 https ://doi.org/10.1089/ jpm. 2014.0070

[12] von Gunten C, Ferrell B. Medical and nursing education \& training. In: Kelley A, Meier D, editors. Meeting the needs of older adults with serious illness: Challenges and opportunities in the age of health care reform. New York, NY: Springer; 2014. 225-36 p. https://doi.org/10.1007/978-1-4939-0407-5_16

[13] Benner P, Sutphen M, Leonard V, et al. Educating nurses: A call for radical transformation. 1st ed. San Francisco: Jossey-Bass; 2010. 288 p.
[14] American Association of Colleges of Nursing. The essentials of baccalaureate education for professional nursing practice [Internet]. Washington, D.C.: American Association of Colleges of Nursing; 2008; 1-63 p. Available from: http://www. aacn.nche.edu/pu blications/order-form/baccalaureate-essentials

[15] National Council of State Boards of Nursing. NCLEX-RN examination: Test plan for the National Council Licensure Examination for registered nurses. Chicago, IL: National Council of State Boards of Nursing; 2015.

[16] Lippe MP, Carter P. End-of-life care teaching strategies in prelicensure nursing education: An integrative review. J Hosp Palliat Nurs. 2015 Feb; 17(1): 31-9. https://doi.org/10.1097/NJH.0000 000000000118

[17] Ferrell B, Malloy P, Mazanec P, et al. CARES: AACN's new competencies and recommendations for educating undergraduate nursing students to improve palliative care. J Prof Nurs. 2016 Jul; 47(6): 2526. https://doi.org/10.1016/j.profnurs.2016.07.002

[18] Stetler C, Legro M, Wallace C, et al. The role of formative evaluation in implementation research and the QUERI experience. J Gen Intern Med. 2006; 21(S2): S1-9. PMid:16637954 https: //doi.org/10.1007/s11606-006-0267-9

[19] Keating SB. Curriculum development and evaluation in nursing. In: Keating S, editor. Section 3, Needs Assessment and financial support for curriculum development. 3rd ed. New York, NY: Springer; 2015; 107-20 p.

[20] Lippe M, Volker D, Jones T, et al. Evaluating end-of-life care education within nursing programs: A method for targeted curriculum evaluation. J Hosp Palliat Nurs. 2017 Jun; 19(3): 266-74. https : //insi ghts . ovid. com/crossref ?an=00129191-201706000-00014

[21] Peters L, Cant R, Payne S, et al. How death anxiety impacts nurses' caring for patients at the end of life: A review of literature. Open Nurs J. 2013; 7: 14-21. PMid:23400515 https ://doi.org/10.2 174/1874434601307010014

[22] Lindley LC, Herr KA, Norton SA. The role of hospice and palliative care nurses in quality improvement. J Hosp Palliat Nurs. 2017; 19(2): 160-165. https://doi.org/10.1097/NJH.0000000000000324 